\title{
Author Correction: Boosting output performance of sliding mode triboelectric nanogenerator by charge space-accumulation effect
}

Wencong He, Wenlin Liu (1), Jie Chen, Zhao Wang, Yike Liu, Xianjie Pu, Hongmei Yang, Qian Tang, Huake Yang, Hengyu Guo (D) \& Chenguo Hu (D)

Correction to: Nature Communications https://doi.org/10.1038/s41467-020-18086-4, published online 26 August 2020.

The original version of this Article contained an error in Fig. 1j, where the correct $Y$-axis unit is " $\mu \mathrm{C}$ " instead of "mC".

This has been corrected in both the PDF and HTML versions of the Article.

Published online: 09 September 2020

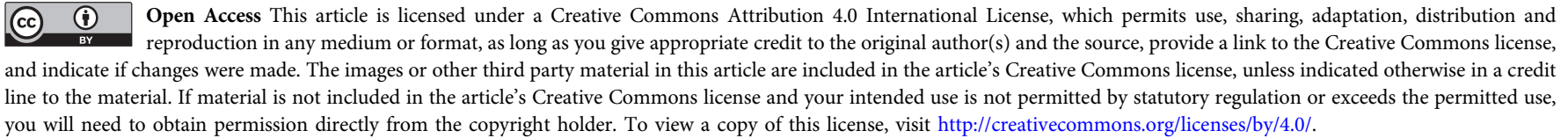

you will need to obtain permission directly from the copyright holder. To view a copy of this license, visit http://creativecommons.org/licenses/by/4.0/.

(c) The Author(s) 2020 